\title{
Surface wind-stress threshold for glacial Atlantic overturning
}

\author{
Marisa Montoya ${ }^{1}$ and Anders Levermann ${ }^{2,3}$ \\ Received 2 November 2007; revised 21 December 2007; accepted 31 December 2007; published 7 February 2008.
}

[1] Using a coupled model of intermediate complexity the sensitivity of the last glacial maximum (LGM) Atlantic meridional overturning circulation (AMOC) to the strength of surface wind-stress is investigated. A threshold is found below which North Atlantic deep water formation (DWF) takes place south of Greenland and the AMOC is relatively weak. Above this threshold, DWF occurs north of the Greenland-Scotland ridge, leading to a vigorous AMOC. This nonlinear behavior is explained through enhanced salt transport by the wind-driven gyre circulation and the overturning itself. Both pattern and magnitude of the Nordic Sea's temperature difference between strong and weak AMOC states are consistent with those reconstructed for abrupt climate changes of the last glacial period. Our results thus point to a potentially relevant role of surface winds in these phenomena. Citation: Montoya, M., and A. Levermann (2008), Surface wind-stress threshold for glacial Atlantic overturning, Geophys. Res. Lett., 35, L03608, doi:10.1029/ 2007 GL032560.

\section{Introduction}

[2] Simulating the climate of the last glacial maximum (LGM, ca. 21,000 years ago) remains a major challenge for climate modeling. One of the quantities showing the largest spread among models is the Atlantic meridional overturning circulation (AMOC). The recent Paleoclimate Modelling Intercomparison Project Phase II (PMIP2) revealed a range of $\pm 40 \%$ in the deviations with respect to the Holocene in the simulated LGM AMOC strength in nine coupled climate models [Weber et al., 2007]. Reconstructions indicate glacial AMOC strength values ranging from a decrease of up to $30 \%$ to a slight increase [Marchal et al., 2000].

[3] Investigating the glacial AMOC response requires an assessment of its driving mechanisms, surface winds and vertical mixing [Kuhlbrodt et al., 2007], at the time. Surface winds force the ocean circulation both directly, through their effect on the large-scale flow [Toggweiler and Samuels, 1998; Wunsch, 1998], and indirectly, by enhancing vertical mixing [Wunsch and Ferrari, 2004]. Stronger glacial meridional surface temperature gradients and evidence mainly from ice-core data for largely increased dust and sea-salt concentrations have led to the general assumption of considerably stronger than present surface winds, possibly by more than 50\% [Crowley and North, 1991, and references therein]. However, enhanced aerosol concentrations also

\footnotetext{
${ }^{1}$ Departamento de Astrofísica y Ciencias de la Atmósfera, Universidad Complutense de Madrid, Madrid, Spain.

${ }^{2}$ Earth System Analysis, Potsdam Institute for Climate Impact Research, Potsdam, Germany.

${ }^{3}$ Institute of Physics, Potsdam University, Potsdam, Germany.
}

Copyright 2008 by the American Geophysical Union. 0094-8276/08/2007GL032560 reflect changes in the sources such as enhanced aridity. While the latter effect can be isolated in Greenland via the greater glacial dust particle sizes reflecting a more efficient large-scale atmospheric transport [Ruth et al., 2003], the results for Antarctica are ambiguous [Delmonte et al., 2004]. Models furthermore show enhanced westerlies but not uniformly enhanced surface winds [e.g., Hewitt et al., 2003; Otto-Bliesner et al., 2006]. Thus, glacial wind-stress is presently poorly constrained, and even weakened winds cannot be ruled out. Here we assess the impact of the latter uncertainty on the glacial AMOC strength.

\section{Glacial Simulation}

[4] The model used in this study is the CLIMBER-3 $\alpha$ model [Montoya et al., 2005]. Its atmospheric component is a statistical-dynamical model [Petoukhov et al., 2000]. Its oceanic component contains the GFDL MOM-3 ocean general circulation model, with a horizontal resolution of $3.75^{\circ}$ and 24 vertical levels, and the ISIS thermodynamicdynamic snow and sea-ice model [Fichefet and Maqueda, 1997]. The version used herein includes a few modifications with respect to the standard configuration described by Montoya et al. [2005] in order to further improve the model's performance for the Holocene (preindustrial) climate (see auxiliary material) ${ }^{1}$. To simulate the LGM climate, the PMIP2 (available at http://pmip2.1sce.ipsl.fr) forcing and boundary conditions were imposed, namely: changes in insolation, a reduced equivalent atmospheric $\mathrm{CO}_{2}$ concentration of $167 \mathrm{ppmv}$ to account for the lowered $\mathrm{CH}_{4}, \mathrm{~N}_{2} \mathrm{O}$ and $\mathrm{CO}_{2}$ concentrations, the ICE-5G ice-sheet reconstruction [Peltier, 2004], and land-sea mask changes plus a global increase of salinity by 1 psu to account for the $\sim 120 \mathrm{~m}$ sea-level lowering. Oceanic bathymetry, vegetation, and river-runoff routing were unchanged with respect to the Holocene simulation.

[5] Due to the coarse resolution of its atmospheric component, the simulated surface winds are not adequate to force the ocean. For experiments representing modest deviations with respect to the preindustrial climate, an anomaly model was implemented in which the wind-stress anomalies relative to the control run are computed and added to climatological data [Montoya et al., 2005]. This approach, however, is not appropriate for a considerably different climate such as that of the LGM. In order to investigate the sensitivity of the glacial AMOC to this field, the model was integrated to equilibrium with the Trenberth et al. [1989] surface windstress climatology multiplied globally by varying factors $\alpha \in$ $[0.5,2]$ (hereafter, $\operatorname{LGM} \alpha$ ). To assess the potential of multiple stable AMOC states, equilibrium simulations with either $\alpha=1$ or $\alpha=2$ (denoted LGM $\alpha$-weak and LGM $\alpha$ -

\footnotetext{
${ }^{1}$ Auxiliary materials are available in the HTML. doi:10.1029/ 2007 GL032560.
} 


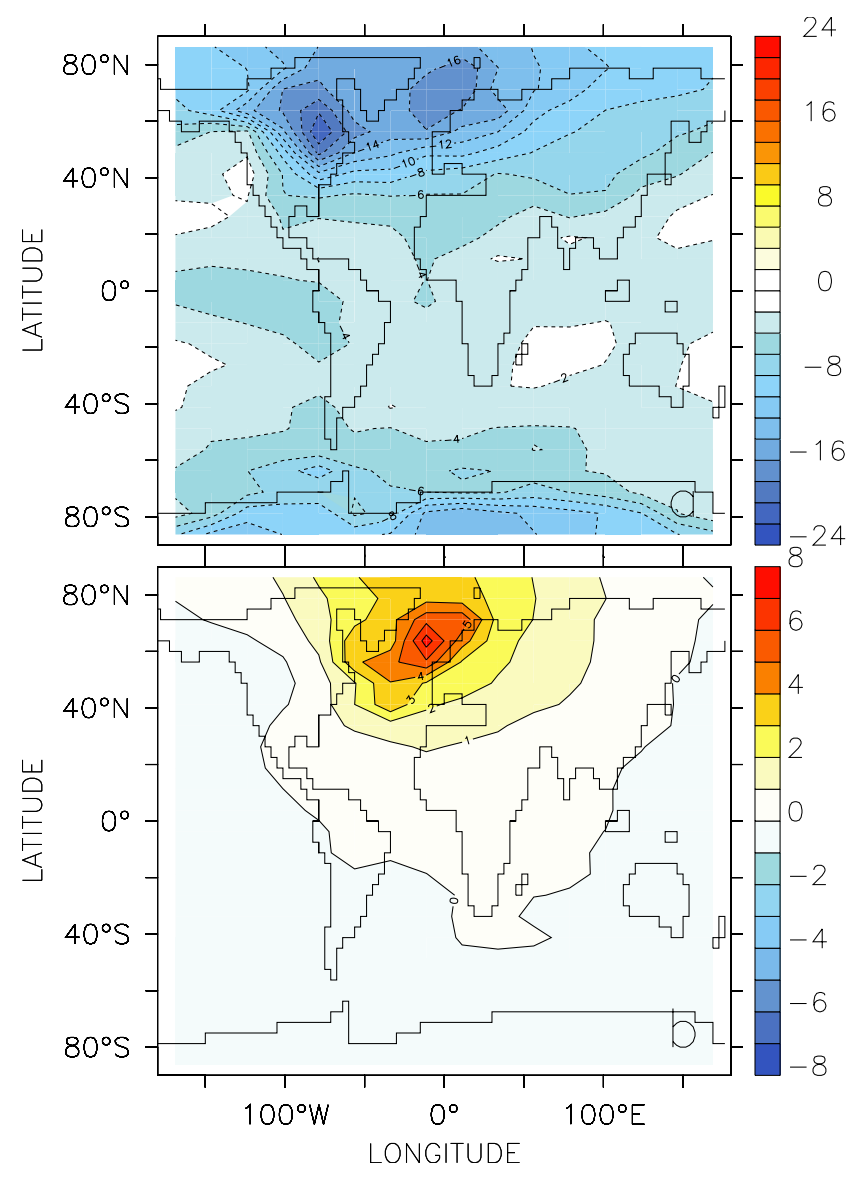

Figure 1. Mean annual surface air temperature (SAT) difference between (a) LGM1.7-weak and HOLO and (b) LGM1.7-strong and LGM1.7-weak (in K).

strong, respectively) were used as initial conditions. Note that our model does not include a wind-dependent parameterization of background vertical mixing. Thus our study focuses on the effect of varying surface winds on the largescale oceanic flow.

[6] In the LGM1.7-weak simulation, with surface windstress enhanced by $70 \%$ and initialized from LGM1, surface air temperature (SAT) shows an overall decrease with respect to the Holocene simulation (hereafter, HOLO) with maximum anomalies above $16 \mathrm{~K}$ over northern North America and the Nordic Seas (Figure 1a). The globally averaged SAT anomaly decreases from $-5.9 \mathrm{~K}$ in LGM0.5 compared to HOLO to $-4.1 \mathrm{~K}$ in LGM2, while the tropical sea surface temperature (SST) anomaly increases from $-2.0 \mathrm{~K}$ in LGM0.5 to $-2.6 \mathrm{~K}$ in LGM2 (see auxiliary material Table S1 and Figure S1). These values are roughly halfway between the tropical cooling estimates of $1-2 \mathrm{~K}$ by the CLIMAP Project Members [1976] reconstruction and of 4-5 K from coral data [Guilderson et al., 1994]. They are consistent both with models and recent alkenone data indicating tropical cooling of about $2 \mathrm{~K}$ and larger decreases at higher latitudes [Rosell-Melé et al., 2004]. Differences in the temperature response simulated in the LGM runs reflect differences in the AMOC strength and associated heat transport, as will become apparent below.

\section{AMOC Threshold Behavior}

[7] The simulated LGM AMOC strength increases continuously with surface wind-stress up to $\alpha_{c} \equiv 1.7$. For $\alpha_{c} \equiv$ 1.7 and the LGM1-initialization, the simulated glacial AMOC strength of $\sim 11 \mathrm{~Sv}$ (Figure $2 \mathrm{~b}$ ) is consistent with paleodata indicating glacial AMOC rates ranging from up to $30 \%$ lower to slightly larger than present [Marchal et al., 2000] (see auxiliary material Figure S2). In this wind-stress regime, deep water formation (DWF) takes place south of the Greenland-Scotland ridge. At $\alpha=\alpha_{c} \equiv 1.7$ a threshold, associated with a drastic AMOC increase of more than $10 \mathrm{~Sv}$, is observed (Figure 3). In the vicinity of this threshold $(\alpha \simeq 1.7-1.75)$ the AMOC exhibits two stable states, with weak and strong circulation, respectively.

[8] This nonlinear behavior is intimately related to the existence of DWF in the Nordic Seas, a vigorous overflow and associated entrainment of surrounding water masses (Figure 2c). The dynamical mechanism is based on an altered salinity distribution in the North Atlantic. Enhanced surface wind-stress increases the horizontal gyre circulation both in the subtropics and the subpolar region. As a consequence, more salt is transported from the Tropics to the North Atlantic in the upper ocean layers. The section of salinity difference between LGM1 and LGM1.7-weak (Figure 4a) shows that gyres transport more saline waters from the tropics northward

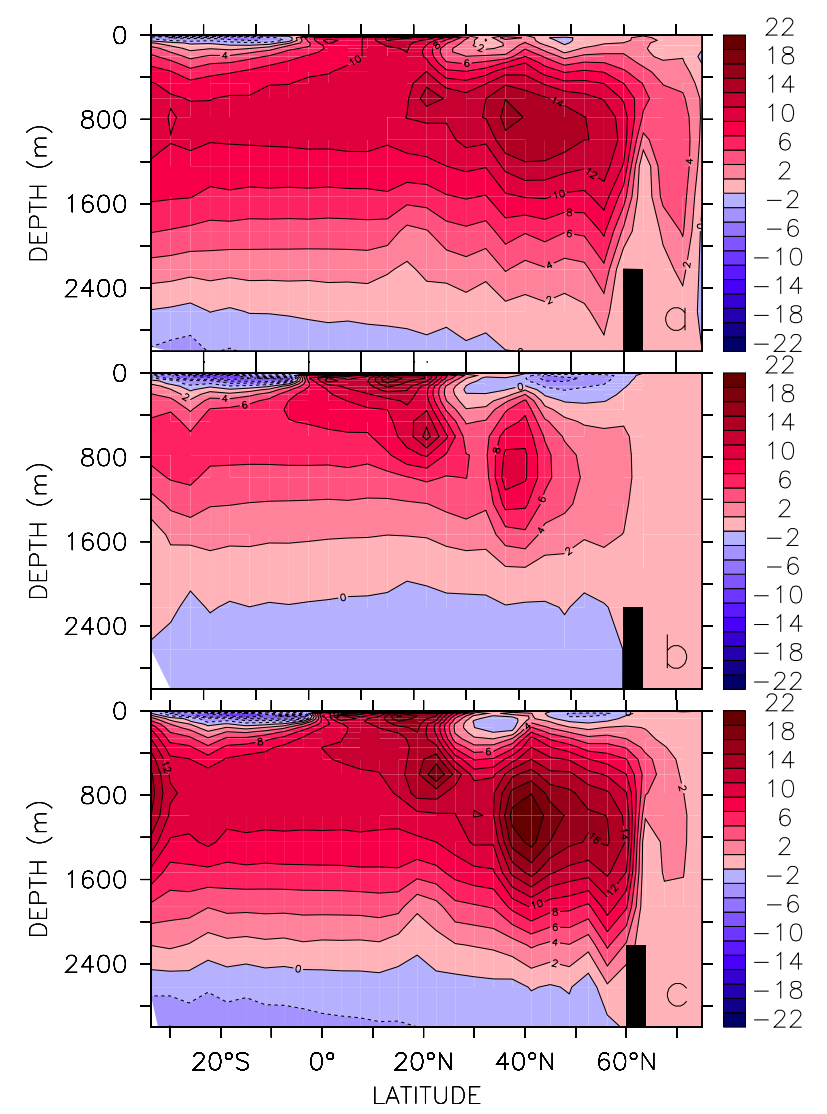

Figure 2. Meridional overturning streamfunction in the Atlantic Ocean for (a) HOLO, (b) LGM1.7-weak, and (c) LGM1.7-strong, in Sv (contour interval is $2 \mathrm{~Sv}$ ). 


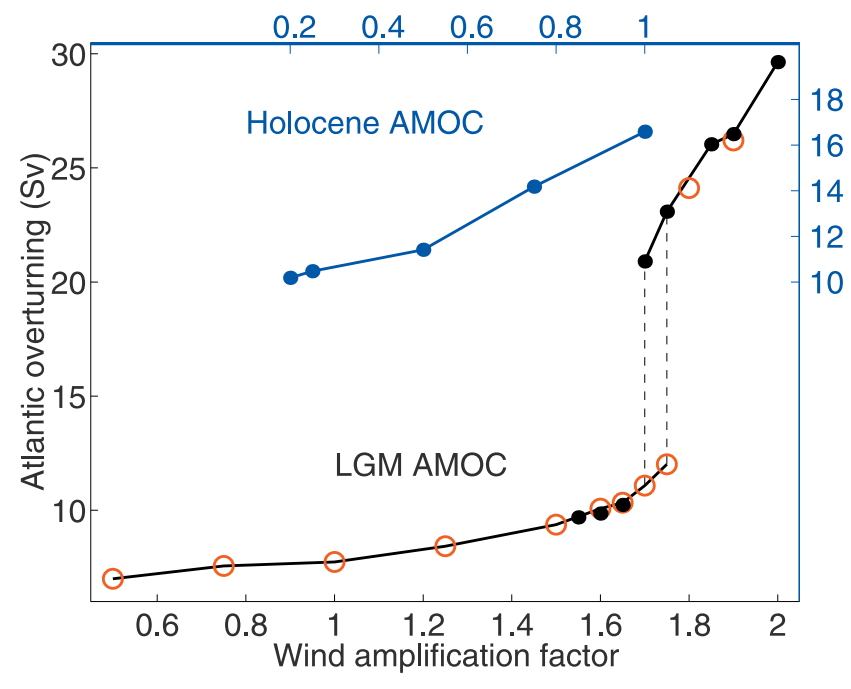

Figure 3. AMOC strength as a function of wind-stress enhancement factor $\alpha$ for the LGM (black) and the Holocene (blue). Full black dots and open red circles indicate LGM equilibrium simulations starting from LGM2 (LGM $\alpha$-strong) and LGM1 (LGM $\alpha$-weak), respectively.

of $30^{\circ} \mathrm{N}$ within the upper $350 \mathrm{~m}$. Higher subtropical SSTs also result in reduced freshwater flux through enhanced evaporation and thereby higher subtropical surface salinities, but the relevant mechanism at high northern latitudes is increased salt transport (see auxiliary material Figure S3). Up to $\alpha \leq 1.7$ the increase in AMOC is thus gradual in response to a gradual increase in gyre salinity transport. In this regime, deep convection and DWF are confined to the region south of the Greenland-Scotland ridge. For $\alpha>1.7$ the gyre salinity transport to the Nordic Seas is sufficient to induce DWF there (Figure 5) and strengthen the AMOC. The enhanced overturning triggers a positive salt-advection feedback [Rahmstorf, 1996]. More salt is transported from the south towards high northern latitudes by the AMOC and consequently, salinity increases in the Nordic Seas and the overturning further strengthens.

[9] To assess whether this behavior is unique to the LGM, several simulations were carried out for the Holocene by reducing the wind-stress globally by a factor $\alpha \in[0.2,1]$ (note that as shown by Figure 2a, for $\alpha=1 \mathrm{DWF}$ in the model in the Holocene already takes place in the Nordic Seas). In this case, contrarily to the LGM, the overflow increases continuously with wind-stress (not shown) and the AMOC strength increase with the wind-stress is roughly linear (Figure 3).

[10] To determine the region in which the wind enhancement is most relevant for the glacial AMOC, additional simulations were performed in which the wind-stress was enhanced locally by $100 \%(\alpha=2)$, while unchanged elsewhere $(\alpha=1)$. In particular, runs were carried out with $\alpha=2$ only in the Northern Hemisphere, the North Atlantic mid-high latitudes, or the Southern Ocean. Only the first of these runs yielded a relatively strong AMOC of ca. $20 \mathrm{~Sv}$ with DWF in the Nordic Seas. Thus, although the role of the winds further south is not negligible, enhanced wind-stress in the whole North Atlantic is critical.

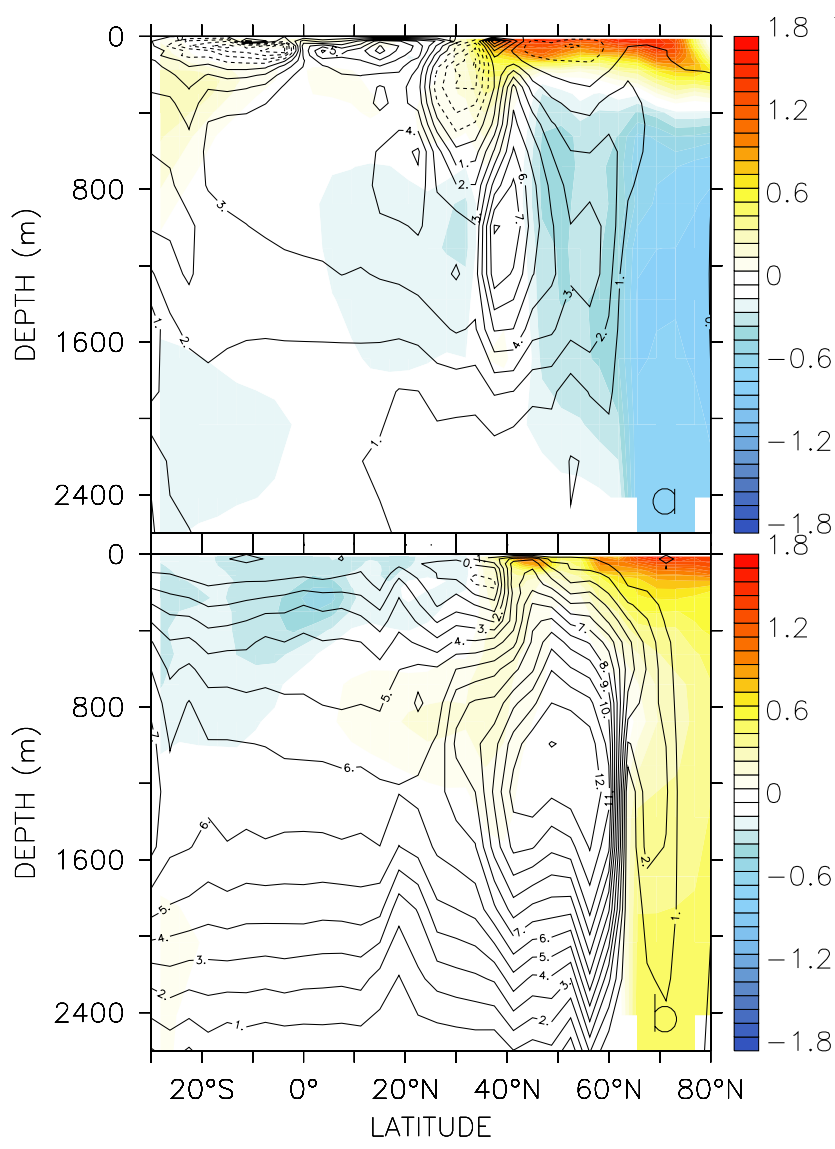

Figure 4. Difference in salinity (in psu) and overturning streamfunction (in Sv) in the Atlantic: (a) LGM1.7-weak minus LGM1 and (b) LGM1.7-strong minus LGM1.7weak. Contour interval is $1 \mathrm{~Sv}$.

[11] Our results support a strengthening of the AMOC found by Häkkinen [2001] in response to an increased subpolar gyre. Note that our findings are not in contradiction with earlier studies which found a bistability of the subpolar gyre as a baroclinic response of the subpolar

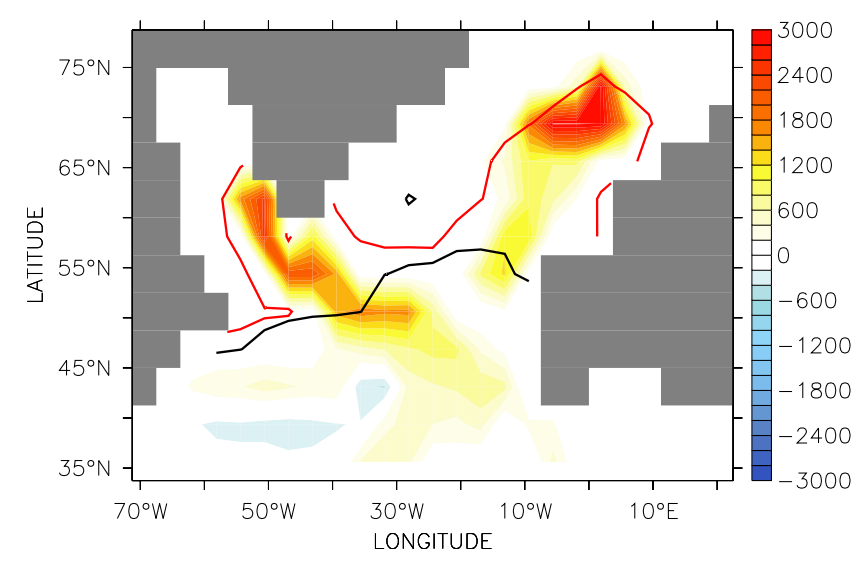

Figure 5. Difference in maximum mixed-layer depth (in $\mathrm{m}$ ) between the LGM1.7-strong and LGM1.7-weak together with the respective locations of the $80 \%$ northern winter (January-April) average sea-ice concentration (LGM1.7-weak, black; LGM1.7-strong, red). 
region, where wind stress was not relevant for the transition between two different subpolar gyre states [Levermann and Born, 2007].

[12] In the glacial simulations, the stronger AMOC is associated with a stronger North Atlantic current and poleward heat transport. Together with the strong decrease in sea-ice concentration (Figure 5) and the positive sea-ice albedo-temperature feedback this leads to Nordic Seas' SATs increased by up to $8 \mathrm{~K}$ relative to LGM1.7-weak (Figure 1b).

\section{Conclusions and Discussion}

[13] We have investigated the sensitivity of LGM climate simulations to global changes in oceanic surface wind-stress by prescribing the latter to be proportional to present day observations. Note that it is likely that wind-stress differences between the Holocene and the LGM will vary regionally, which is not taken into account here and will be the scope of future work. In addition, CLIMBER-3 $\alpha$ does not contain atmospheric variability which might be relevant for the stability of the ocean circulation.

[14] For present winds the simulated LGM AMOC weakens considerably with respect to the Holocene. However, the global MOC strength, including both northern and southern DWF sources, is roughly the same (not shown), reflecting that the total energy input into the ocean through winds and mixing is the same. Yet, the AMOC characteristics depend not only on the energy input but also on the buoyancy forcing, which limits DWF [Kuhlbrodt et al., 2007]. Thus, the weaker AMOC is not inconsistent with equal or somewhat stronger surface winds.

[15] The AMOC strength increases with the surface wind strength, exhibiting a threshold behavior with respect to the latter. In the North Atlantic both pattern and magnitude of the simulated temperature difference between strong and weak AMOC states are consistent with those expected during abrupt climate changes of the last glacial period, in particular Dansgaard-Oeschger events [Grootes et al., 1993]. This suggests changes in surface wind strength could trigger such abrupt warming events through latitudinal shifts in North Atlantic DWF sites. The basic mechanism is thus the same as suggested by Ganopolski and Rahmstorf [2001], while the trigger in our case are variations in surface winds, as opposed to surface freshwater flux variations in the latter study. This behavior is furthermore absent in the simulated Holocene climate, where a roughly linear increase of the AMOC with wind-stress is found.

[16] It has been suggested that sea-ice changes in the North Atlantic are necessary in order to explain the magnitude of the Dansgaard-Oeschger warming signal observed in Greenland [ $\mathrm{Li}$ et al., 2005]. Here we show that if the glacial climate were close to a threshold, relatively small changes in surface wind strength might be enough to promote DWF in the Nordic Seas and induce large regional temperature anomalies associated with strong sea ice retreat. Our results thus point to a potentially relevant role of changes in surface wind strength in abrupt climate change during the last glacial period.

[17] Acknowledgments. M. M. was funded by the Ramón y Cajal Program and project CGL2005-06097/CLI of the Spanish Ministry for
Science and Education. We are grateful to J. R. Toggweiler for constructive criticism which has improved this manuscript.

\section{References}

CLIMAP Project Members (1976), The surface of the ice-age, Science, 191, $1131-1137$.

Crowley, T. J., and G. R. North (1991), Paleoclimatology, 339 pp., Oxford Univ. Press, New York.

Delmonte, B., J. R. Petit, K. K. Andersen, I. Basile-Doelsch, V. Maggi, and V. Y. Lipenkov (2004), Dust size evidence for opposite regional atmospheric circulation changes over east Antarctica during the last climatic transition, Clim. Dyn., 23, 427-438.

Fichefet, T., and M. A. M. Maqueda (1997), Sensitivity of a global sea ice model to the treatment of ice thermodynamics and dynamics, J. Geophys. Res., 102, 12,609-12,646.

Ganopolski, A., and S. Rahmstorf (2001), Rapid changes of glacial climate simulated in a coupled climate model, Nature, 409, 153-158.

Grootes, P. M., M. Stuiver, J. W. C. White, S. Johnsen, and J. Jouzel (1993), Comparison of oxygen isotope records from the GISP2 and GRIP Greenland ice cores, Nature, 366, 552-554.

Guilderson, T. P., R. G. Fairbanks, and J. L. Rubenstone (1994), Tropical temperature variations since 20,000 years ago: Modulating interhemispheric climate change, Science, 263, 663-665.

Häkkinen, S. (2001), Variability in sea surface height: A qualitative measure for the meridional overturning in the North Atlantic, J. Geophys. Res., 106, 13,837-13,848.

Hewitt, C. D., R. J. Stouffer, A. J. Broccoli, J. F. B. Mitchell, and P. J. Valdes (2003), The effect of ocean dynamics in a coupled GCM simulation of the Last Glacial Maximum, Clim. Dyn., 20, 203-218.

Kuhlbrodt, T., A. Griesel, M. Montoya, A. Levermann, M. Hofmann, and S. Rahmstorf (2007), On the driving processes of the Atlantic meridional overturning circulation, Rev. Geophys., 45, RG2001, doi:10.1029/ 2004RG000166.

Levermann, A., and A. Born (2007), Bistability of the Atlantic subpolar gyre in a coarse-resolution climate model, Geophys. Res. Lett., 34, L24605, doi:10.1029/2007GL031732.

Li, C., D. S. Battisti, D. P. Schrag, and E. Tziperman (2005), Abrupt climate shifts in Greenland due to displacements of the sea ice edge, Geophys. Res. Lett., 32, L19702, doi:10.1029/2005GL023492.

Marchal, O., R. François, T. F. Stocker, and F. Joos (2000), Ocean thermohaline circulation and sedimentary $231 \mathrm{~Pa} / 230 \mathrm{Th}$ ratio, Paleoceanography, 15(6), 625-641.

Montoya, M., A. Griesel, A. Levermann, J. Mignot, M. Hofmann, A. Ganopolski, and S. Rahmstorf (2005), The earth system model of intermediate complexity CLIMBER-3 $\alpha$. Part I: Description and performance for present day conditions, Clim. Dyn., 25, 237-263.

Otto-Bliesner, B. L., E. C. Brady, G. Clauzet, R. Tomas, S. Levis, and Z. Kothavala (2006), Last Glacial Maximum and Holocene climate in CCSM3, J. Clim., 19, 2526-2544.

Peltier, W. R. (2004), Global glacial isostasy and the surface of the ice-age Earth: The ICE-5G (VM 2) model and GRACE, Annu. Rev. Earth Planet. Sci., 32(1), 111-149.

Petoukhov, V., A. Ganopolski, V. Brovkin, M. Claussen, A. Eliseev, C. Kubatzki, and S. Rahmstorf (2000), CLIMBER-2: A climate system model of intermediate complexity. Part I: Model description and performance for present climate, Clim. Dyn., 16, 1-17.

Rahmstorf, S. (1996), On the freshwater forcing and transport of the Atlantic thermohaline circulation, Clim. Dyn., 12, 799-811.

Rosell-Melé, A., E. Bard, K.-C. Emeis, B. Grieger, C. Hewitt, P. J. Müller, and R. R. Schneider (2004), Sea surface temperature anomalies in the oceans at the LGM estimated from the alkenone- $\mathrm{U}_{37}^{K^{\prime}}$ index: Comparison with GCMs, Geophys. Res. Lett., 31, L03208, doi:10.1029/ 2003GL018151.

Ruth, U., D. Wagenbach, J. P. Steffensen, and M. Bigler (2003), Continuous record of microparticle concentration and size distribution in the central Greenland NGRIP ice core during the last glacial period, J. Geophys. Res., 108(D3), 4098, doi:10.1029/2002JD002376.

Toggweiler, J. R., and B. Samuels (1998), On the ocean's large scale circulation in the limit of no vertical mixing, J. Phys. Oceanogr., 28, $1832-1852$.

Trenberth, K., J. Olson, and W. Large (1989), A global ocean wind stress climatology based on ECMWF analyses, Tech. Rep. NCAR/TN-338+STR, Natl. Cent. for Atmos. Res., Boulder, Colo.

Weber, S. L., S. S. Drijfhout, A. Abe-Ouchi, M. Crucifix, M. Eby, A. Ganopolski, S. Murakami, B. Otto-Bliesner, and W. R. Peltier (2007), The modern and glacial overturning circulation in the Atlantic Ocean in PMIP coupled model simulations, Clim. Past, 3(1), 51-64.

Wunsch, C. (1998), The work done by the wind on the oceanic general circulation, J. Phys. Oceanogr., 28, 2332-2340. 
Wunsch, C., and R. Ferrari (2004), Vertical mixing, energy, and the general circulation of the oceans, Annu. Rev. Fluid Mech., 36, 281-314.

A. Levermann, Earth System Analysis, Potsdam Institute for Climate Impact Research, Telegrafenberg A62, D-14473 Potsdam, Germany.
M. Montoya, Departamento de Astrofísica y Ciencias de la Atmósfera, Universidad Complutense de Madrid, Ciudad Universitaria, E-28040 Madrid, Spain. (marisa.montoya@fis.ucm.es) 